\title{
A rare case of heterotopic ossification within the small bowel mesentery (intra abdominal myositis ossificans)
}

\author{
Ankur Jhanwar, $\mathrm{MBBS}^{1}$, Radheyshyam Meena, MBBS $\mathrm{MS}^{2}$, Neelam Sharma, MBBS $\mathrm{MS}^{3}$, \\ Pawan Bansal, MBBS MS 4
}

1 Senior Resident, Departmrnt Of Surgery, Government Medical College, Kota, Rajasthan, India.

2 Professor and Head Department Of Surgery, Government Medical College, Kota, Rajasthan, India.

3 Assistant Professor, Medical College, Jhalawar, Rajasthan, India.

4 Assistant Professor, Government Medical College, Kota, Rajasthan, India.

\begin{abstract}
There are only few reports of heterotopic mesenteric ossification (HMO) in the medical literature. Most cases are poorly defined lesions in intra-abdominal structures usually involving the mesentery causing intestinal obstruction [1]. Intraabdominal heterotopic ossification is a very uncommon disorder [2]. Here we report a case of a 11 year old male who had heterotopic bone formation in the small bowel mesentery. An initial diagnosis of ileoileal intussusception was considered. Histopathologic examination of the tumour mass show heterotopic mesenteric ossification.
\end{abstract}

Key words: Heterotopic mesenteric ossification; Small bowel mesentery.

Heterotopic bone formation has been previously noted in laparotomy scars [3], and has been reported rarely within the abdominal cavity specifically in mesenteric location [4]. Heterotopic ossification (HO) is a metaplastic process that usually follows trauma and infections. Heterotopic ossification can be recurrent and should not be misinterpreted for cancer [5]. The most familiar synonym of this process in soft tissue is myositis ossificans. In 1999, Wilson et al suggested the designation heterotopic mesenteric ossification (HMO) [2]. These lesions share with classical soft tissue myositis ossificans, the chararteristic of frequent association with trauma, rapid but predictable course, and mesenchymal proliferation with zoning phenomenon. Myositis ossificans is a misnomer since this process is not confined to muscles and usually exhibits little inflammation [6]. Rarely lesions occur intra-abdominally, with the most common location being in the mesentery. Generally, these patients are male, elderly and have a history of abdominal trauma and/or surgeries and present with bowel obstruction [7]. This entity should be recognised radiologically and distinguished from dystrophic calcification, osseous neoplasia. A trabecular architecture evi-

Correspondence: Ankur Jhanwar, Senior Resident,

Departmrnt Of Surgery,

Government Medical College, Kota, Rajasthan, India

E-mail: drankurstanley01@gmail.com dent at radiography is highly suggestive of ossification. Also, the presence of mature trabeculae distinguishes heterotopic mesenteric ossification from osseous neoplasia. Finally, pre-operative CT may provide confirmatory evidence of any suspicious trabecular pattern seen on abdominal radiography.

Case report: A 11 year old male presented with a complaint of abdominal pain of 10 days, vomiting, mild abdominal distension, and constipation of a day's duration. There was no history of trauma or previous abdominal surgery. His abdominal examination was normal except for the presence of a mobile mass in the right iliac fossa. The rectal examination was normal.X-ray of the abdomen did not reveal any abnormality. Ultrasound abdomen suggested intussusception, either ileo-ileal or ileo-colic. Based on clinical and radiological findings a diagnosis of intussusception was made. Routine haematological indices were normal. An exploratory laparotomy was performed through a right paramedian incision.

At laparotomy, no intussusception was found but a 5 x 3.5 $\mathrm{x} 5 \mathrm{~cm}$ hard nodule was felt in the small bowel mesentery. It was thought to be a mesenteric lymph node, excised and the mesentery repaired. No other pathology was detected. Macroscopically the nodule was well defined with a yellowish external surface. Cut section revealed a cavity with yellowish serous content and necrotic mucinous material.

The patient made an uneventful recovery. 
Histology revealed a lesion mainly composed of hypercellular populations of immature stromal cells. The stromal cells including osteoblasts lacked cytologic features of malignancy.

Circumscribed areas showing well formed bony trabeculae with osteoblastic stromal features were suggestive of heterotopic bone in mesentery.

Discussion: Awareness of the existence of HMO is important to avoid an erroneous diagnosis of extraskeletal osteosarcoma which is an important differential diagnosis. $[3,4]$. Typical zonation of stromal cells proliferation, immature osteoid and mature bone formation and lack of cytologic atypia are important clues for the identification of HMO.

HMO has a strong male preponderance with 26 reported cases and only two reported cases in females. Most present with small bowel obstruction and only three among 28 cases were incidental findings.

This presentation of HMO in a child, with the lack of diffuse mesenteric involvement makes it unique.

\section{Refrences}

1. Athanaziol DA, de Carvalhoet ALL, e Silva NO, Athanazio PRF. Heterotopic Intraabdominal ossification: report of a case and review of the literature. $\mathrm{J}$ Bras Patol Med lab. 2009; 45(2): 125-30

2. Wilson JD, Montague CJ, Salcuni P, Bordi C, Rosai J. Heterotopic mesenteric ossification ('intraabdominal myositis ossificans') : report of five cases. Am J Surg pathol.1999; 23(12): 1464-70.
Doi: http://dx.doi.org/10.1097/00000478-19991200000003PMid:10584699

3. Myers MA, Minton, MD. Heterotopic ossifications within the small bowel mesentry. Arch Surg. 1989; 124(8): 982-83.

Doi: http://dx.doi.org/10.1001/archsurg. 1989. 01410080118020

PMid:2527023

4. Bovo G, Romano F, Perego E, Franciosi C, Buffa R et al. Heterotopic mesenteric ossification ('intraabdominal myositis ossificans') : a case report. International Journal of Surgical Pathology. 2004; 12(4): 407-9. Doi: http://dx.doi.org/10.1177/106689690401200416 PMid:15494869

5. Victoria VL, Oliver BL, Edgar F. Postoperative Bowel Perforation due to Heterotopic Ossification (Myositis Ossificans Traumatica): A Case Report and Review of the Literature. Case Reports in Gastrointestinal Medicine 2011;2011:908514.

doi:10.1155/2011/908514

6. Zamolyi RQ, Souza P, Nascimento AG, Unni KK. Intraabdominal myositis ossificans: a report of 9 new cases. International Journal of Surgical Pathology. 2006; 1(14): 37-41

Doi: http://dx.doi.org/10.1177/106689690601400107

7. Patel RM, Weiss SW, Folpe AL. Heterotopic mesenteric ossification: a distinctive pseudosarcoma commonly associated with intestinal obstruction. Am J Surg Pathol. 2006; 30(1): 119-22 